\title{
Netflix e a manutenção de gêneros televisivos fora do fluxo
}

\section{Netflix and the maintenance of television genres out of the flow}

\author{
CECÍl IA A L MEIDA LIMA* \\ Universidade Federal de Pernambuco, Programa de Pós-Graduação em Comunicação. Recife-PE, Brasil \\ Faculdade Boa Viagem, Curso de Comunicação Social. Recife-PE, Brasil
}

DIEGO G O U E I A M REIRA **

Universidade Federal de Pernambuco, Centro Acadêmico do Agreste, Núcleo de Design, Curso de Design e Comunicação Social. Caruaru-PE, Brasil

J A N A I A COSTA CA LAZANS***

Universidade Católica de Pernambuco, Curso de Publicidade e Propaganda. Recife-PE, Brasil

Faculdade Boa Viagem. Recife-PE, Brasil

\section{RESUMO}

O Emmy de 2013 indicou séries produzidas pela Netflix, que nunca passaram por uma grade de programação televisiva. Esse fato abriu oportunidade para discussões sobre o que determina se um produto é televisual ou não, levando em consideração as teorias que definem produtos televisivos a partir da exibição no fluxo contínuo e as teorias que analisam essas produções diante das recorrências de características que denotam a constituição de gêneros textuais televisivos. O presente artigo tem como objetivo principal entender como programas fora do fluxo televisivo podem ser considerados produtos de televisão. Essa análise será realizada a partir das séries criadas pelo Netflix em 2013

Palavras-chave: Televisão, Netflix, gêneros televisivos

\section{ABSTRACT}

The Emmy Awards 2013 nominated Netflix's original series, which have never been in a television schedule. This opened an opportunity for discussions regarding what determines a television product, considering theories that define television products for its continuous flow (within a schedule) and theories that analyze those productions considering textual recurrences that constitute television genres. This paper aims to understand how programs made outside the television flow can be considered to be television products. The objects for that analysis are Netflix's original series developed on 2013.

Keywords: Television, Netflix, television genres

DOI:http://dx.doi.org/10.11.606/issn.19\$2-\$160.v9.i2p.237-256
* Doutoranda pelo programa de PósGraduação em

Comunicação (PPGCOM) da Universidade Federal de Pernambuco (UFPE), é professora do curso de Comunicação Social da Faculdade Boa Viagem (FBV) e pesquisadora do grupo Obitel (Observatório Íbero-Americano da Ficção Televisiva). E-mail: cecilia. almeidarl@gmail.com

**Doutor pelo PPGCOM da UFPE, é docente do curso de Comunicação Social e Design da Universidade Federal de Pernambuco e pesquisador do grupo Obitel. E-mail: dgmgouveia@gmail.com

*** Doutora pelo PPGCOM da UFPE, é coordenadora do curso de Publicidade e Propaganda da Universidade Católica de Pernambuco (UNICAP) e docente da graduação e do mestrado da FBV. E-mail: janaina.calazans@ gmail.com

MATRIZes 


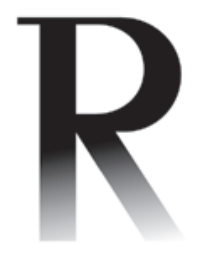

1. Esta e as demais traduções foram realizadas pelos autores.

\section{TELEVISÃO: DEFINIÇÃO EM PROCESSO DE MUDANÇA}

E M 2013, PELA primeira vez em 65 anos, o Emmy Awards, considerado como equivalente ao Oscar para a TV, indicou para a premiação séries distribuídas exclusivamente pela internet. No total, a empresa de produção e divulgação de conteúdo audiovisual online, Netflix, recebeu 14 indicações, sendo nove delas para o drama político House of Cards, três para a comédia Arrested Development e duas para o seriado de horror Hemlock Grove. Diante da escolha do júri do Emmy, o diretor de conteúdo da Netflix, Ted Sarandos, afirmou que a iniciativa ratifica a ideia de que "televisão é televisão, independentemente de como o conteúdo é levado à tela" (Carr, 2013, informação eletrônica) ${ }^{1}$.

Anos atrás, essa declaração seria algo impensável, mas, diante das múltiplas possibilidades de telas que acompanhamos na atual configuração do campo midiático, essa é uma constatação possível, o que nos leva a pensar nos critérios levados em consideração para definir um programa como sendo conteúdo televisivo. Dessa forma, pode-se questionar se ainda é possível afirmar que, para ser nomeado de tal forma, o conteúdo precisaria ter sido exibido dentro de uma grade de programação. Este artigo tem como objetivo principal problematizar como programas fora do fluxo televisivo podem ser considerados produtos de TV. Essa análise será realizada a partir de três séries criadas pela Netflix em 2013, levando em conta as teorizações sobre gêneros textuais televisivos, de modo a verificar a hipótese de que, apesar de as séries nunca terem sido veiculadas como parte de uma grade de programação, ainda assim são reconhecidas como seriados televisivos devido ao uso de recorrências textuais comuns a esse gênero.

Ao problematizar o que define, afinal, o meio televisão, a autora Elizabeth Evans (2011) levanta a pergunta: a televisão seria definida pelos seus conteúdos ou pelos componentes constitucionais da programação, ou seja, imagens em movimento e sons? A pesquisadora ainda questiona se a chave para explicar o que é TV estaria na tecnologia, capaz de enviar sinais analógicos (ou digitais) pela atmosfera ou através de um cabo ou, numa última alternativa, um tipo de combinação entre texto, tecnologia e indústria.

Para tentar responder a essa questão, Evans evoca algumas das teorias mais relevantes acerca do tema. Entre elas, nos interessa particularmente a de Raymond Williams (2004), que situa a televisão numa posição intermediária entre conteúdo e tecnologia, com o seu conceito de fluxo. O autor prefere o termo fluxo em sua análise da televisão como tecnologia e forma cultural, em oposição ao conceito de "distribuição", que, segundo ele, seria limitado e estático. Para ele, o conceito seria fundamental para entender a programação televisiva. Vale ressaltar que Williams publicou seu Television: technology and cultural form em 1975, bem antes da própria televisão a cabo e de diversas 
outras tecnologias que hoje promovem interferências na experiência própria de assistir à televisão, portanto, sua teoria não problematiza essas questões.

Williams utilizou o conceito de fluxo para descrever a natureza estável da programação televisiva, por meio do aparelho, e a maneira como a narrativa e as interrupções comerciais se combinam. Segundo o autor, a televisão não é apenas a disposição de unidades audiovisuais individuais que se sucedem. A TV seria um fluxo constante e planejado: uma sequência transformada pela inclusão de outro tipo de sequência, e assim por diante, de maneira que é o conjunto dessas sequências o que constitui o verdadeiro broadcasting.

Em todos os sistemas de broadcasting desenvolvidos, sua organização característica e, portanto, sua experiência característica é de sequência ou de fluxo. Tal fenômeno de fluxo planejado talvez possa ser a característica definidora do broadcasting, simultaneamente enquanto tecnologia e enquanto forma cultural. (Williams, 2004: 86) ${ }^{2}$

O autor explica: em todos os sistemas de comunicação anteriores ao broadcasting, os itens essenciais eram pontuais. Um livro é lido como um item específico; uma reunião ocorre num local e data particulares; uma peça é apresentada num teatro específico e numa hora específica. A diferença no broadcasting não é apenas que esses eventos estejam disponíveis dentro do lar, por meio de um controle remoto, mas é que o verdadeiro programa que é oferecido é uma sequência ou conjunto de sequências desses e de outros eventos similares. No entanto, o espectador estaria tão acostumado a isso que não percebe - até seu vocabulário foi moldado pela experiência de eventos pontuais. $\mathrm{O}$ autor prossegue afirmando que o ser humano desenvolveu maneiras de responder a um livro particular ou uma peça particular, a partir de experiências de outros livros e peças. Nossos modos de compreensão e de julgamento estão fortemente ligados a essas formas de atenção específicas, isoladas e temporárias.

Williams concorda que outros tipos de comunicação anteriores ao broadcasting também possuem variações internas. Por exemplo, o autor cita as performances dramáticas que podem possuir intervalos musicais ou os jornais, que abordam temas miscelâneos e sem relação entre si, além de anúncios, fotografias, desenhos etc. Essa tendência, em direção a uma variabilidade superior e maior miscelânea de comunicações públicas, é parte da experiência social como um todo. As primeiras fases do broadcasting herdaram essa tradição e trabalharam em cima dela. Eventos pontuais - como o concerto musical, a palestra, o jogo esportivo, a peça musical - poderiam ser transmitidos pelo broadcasting, e, embora ainda fossem tratados como eventos pontuais, estariam formatados como programas, parte de uma programação. Para Williams,
2. Original: "In all developed broadcasting systems the characteristic organisation, and therefore the characteristic experience, is one of sequence or flow. This phenomenon, of planned flow, is then perhaps the defining characteristic of broadcasting, simultaneously as a technology and as a cultural form". 
mesmo o termo programa seria insuficiente para descrever o desenvolvimento do broadcasting: houve uma mudança do conceito de sequência como programação para o conceito de sequência como fluxo contínuo.

Uma programação de broadcasting ainda é uma série de unidades temporais - podemos olhar o horário de determinado programa, ligar a televisão naquele momento e responder ao programa pontualmente, de modo isolado. Entretanto, a forma como se passou a experimentar o broadcasting culturalmente é diferente. Tanto na televisão quanto no rádio, desde seu princípio, havia intervalos entre as unidades, que tinham como função mostrar que, embora o programa tivesse acabado, o serviço ainda estava ativo. Esses intervalos, diz Williams, foram repropostos com o passar do tempo - principalmente porque passaram a ter finalidade commercial e publicitária. Na televisão britânica, as interrupções deveriam ser tão naturais quanto fosse possível. Já na televisão estadunidense, os programas patrocinados incorporavam as interrupções comerciais desde sua concepção inicial, como parte do pacote completo. No entanto, muito embora os próprios espectadores ainda interpretem dessa maneira, para Williams, a noção de interrupção passou a ser inadequada: o que é oferecido não é um programa de unidades isoladas com inserções particulares, mas um fluxo planejado, no qual a sequência é transformada pela inclusão de outro tipo de sequência, de modo que a combinação dessas sequências compõe o fluxo.

Esse fluxo criado pela forma de transmissão da televisão, segundo Williams, passou a ser determinante para que se pudesse avaliar o conteúdo transmitido por um produto, que, na verdade, era transmitido pelo conjunto da programação, e não pelo programa individualmente. $\mathrm{O}$ mesmo produto poderia ter uma função totalmente diferente dentro de outro fluxo. Nesse sentido, não é necessário que o produto tenha sido originalmente criado para a televisão. Como se sabe, as emissoras de televisão incorporam conteúdos audiovisuais de origens diversas à sua noção de fluxo - como filmes feitos inicialmente para o cinema, por exemplo, que passam também a ter inserções comerciais previamente planejadas.

É essa experiência de consumo do fluxo televisivo que passou a sofrer ameaças depois que as emissoras de TV precisaram encarar a concorrência imposta por outros dispositivos, como videocassetes, videogames, computadores, aparelhos de DVD e, mais recentemente, a internet e a quantidade de conteúdos ofertados. A interferência de um número cada vez maior de dispositivos tecnológicos, capazes de conceder ao usuário maior controle no consumo da televisão, tem quebrado o fluxo enquanto característica fundamental do meio - ao menos no sentido de que o fluxo televisivo é determinado por outra pessoa que não o próprio espectador (Lotz, 2007). 
"A televisão tem sido afetada, de modo direto, pelos novos modos de produção das tecnologias da convergência, seja pela emergência dos meios interativos, seja pela circulação de conteúdos por diferentes sistemas de distribuição" (Fechine, 2009: 139). Diante desse novo cenário, muitos embates teóricos têm sido travados, nos últimos anos, a respeito do destino da TV diante das mídias infoeletrônicas. $\mathrm{O}$ cinema e o rádio sobreviveram à TV, o impresso continua existindo mesmo com a internet. A TV resistirá aos novos meios? Essa inquietação tem mobilizado autores de diversos países com experiências audiovisuais, sociais e econômicas diferentes. Muitos pesquisadores vislumbram mudanças tão grandes que não sabem se a nova televisão poderá ser chamada de TV. O autor espanhol Ávarez Monzoncillo (2011) explica que essa nova TV vai permitir ao público assistir aos conteúdos televisivos quando, onde e como quiser.

A ideia de que a TV não está morrendo, está apenas mudando é compartilhada por muitos outros pesquisadores. Não devem ser desconsideradas as mudanças que os novos meios estão causando nos tradicionais, entretanto, melhor do que pensar na morte da TV é apostar na influência recíproca entre meios. $\mathrm{O}$ estadunidense Toby Miller é um dos que acreditam no potencial da televisão:

Imaginar a Internet em oposição à televisão é bobagem; ao contrário, ela é apenas mais uma forma de enviar e receber a televisão. E a TV está se tornando mais popular, não menos. Suspeito que estamos testemunhando uma transformação da $\mathrm{TV}$, ao invés do seu falecimento. O que começou, na maioria dos países, como um meio de comunicação de transmissão nacional dominado pelo Estado, está sendo transformado em um meio de comunicação internacional a cabo, via satélite e Internet, dominado pelo comércio. (Miller, 2009: 22)

Segundo William Urichio, a história da televisão sempre foi uma história de mudanças. "Nós testemunhamos um processo contínuo de transformação em tecnologia, organização textual, estruturas regulatórias e práticas de consumo" (Urichio, 2009: 60)․․ Para Amanda Lotz (2007), à medida que a experiência televisiva ganhou novas capacidades e se difundiu por telas adicionais, as compreensões culturais estabelecidas mudaram, para que ainda possamos continuar a compreender diferentes experiências como assistir televisão. "A televisão pode não estar morrendo, mas mudanças em seu conteúdo e como e onde nós o consumimos complicaram a maneira de pensarmos e entendermos seu papel na cultura" (Lotz, 2007: 30) ${ }^{4}$.

Além da possibilidade de quebra do fluxo, a oferta de conteúdos se tornou mais vasta, acarretando numa maior segmentação do público e consequente fragmentação da audiência televisiva, que se torna mais restrita e especializada.
3. Original: "We have witnessed an ongoing process of transformation in technology, textual organization, regulatory frameworks, and viewing practices".

4. Original: "Television may not be dying, but changes in its content and how and where we view have complicated how we think about and understand its role in the culture". 
A TV a cabo trouxe a programação voltada para nichos de interesse, fator ainda mais enfatizado com a chegada da internet. Assim, embora a televisão ainda possa funcionar como um meio de massa, em muitos casos ela o faz por agregar essas diversas audiências de nicho (Lotz, 2007). Não se trata, portanto, de decretar o fim do broadcasting ou do fluxo televisivo como um todo, mas de dar aos usuários a possibilidade de ter acesso aos conteúdos - enquanto unidades pontuais - que mais atendem aos seus interesses. Dessa forma, a indústria televisiva vive um momento de coexistência entre os regimes do broadcast, do narrowcast e da oferta de conteúdos sob demanda, que dão ao espectador o direito de assistir aos programas no momento em que lhe for mais conveniente, sem depender de uma grade de programação, por meio da internet (Urichio, 2009).

Desde 1997, a Netflix se apresenta como serviço pioneiro nesse sentido, embora não seja o único, oferecendo para seus assinantes um catálogo de filmes e programas de TV para serem consumidos por meio de uma diversidade de aparelhos e gadgets compatíveis, desde que estejam conectados à internet. A princípio, uma espécie de videolocadora virtual, cuja assinatura mensal é fixa e promove acesso ilimitado ao acervo. Hoje, a empresa está no processo de consolidar-se também como uma produtora e emissora de conteúdo audiovisual online.

Indicados em pé de igualdade com séries de canais da televisão aberta e a cabo, os seriados originais da Netflix nunca foram exibidos numa grade de programação. Ainda assim, são considerados pela crítica e pelo senso comum como conteúdos televisivos. Para explorar essa aparente contradição, se faz pertinente investigar as teorias sobre gêneros discursivos.

\section{UMA QUESTÃO DE GÊNERO}

Os enunciados televisuais são apresentados aos espectadores numa variabilidade praticamente infinita. A rigor, poder-se-ia dizer que cada enunciado concreto é uma singularidade que se apresenta de forma única, mas foi produzido dentro de uma certa esfera de intencionalidades, sob a égide de uma certa economia, com vistas a abarcar um certo campo de acontecimentos, atingir um certo segmento de telespectadores e assim por diante. Dessa maneira, malgrado único em sua ocorrência singular, ele ilustra ou espelha uma determinada possibilidade de utilização dos recursos expressivos da televisão, um certo conceito de televisão, e isso se expressa não apenas nos seus conteúdos verbais, figurativos, narrativos e temáticos, como também no modo de manejar os elementos dos códigos televisuais. (Machado, 2001: 70) 
Se de um lado já não podemos afirmar com precisão se a definição de televisão estaria essencialmente ancorada à ideia do fluxo decorrente da sequência da grade de programação, de outro, parece seguro dizer que a televisão, no decorrer de sua história, gerou formas relativamente estáveis de linguagem e conteúdo, que são reconhecidas enquanto tais pela audiência independentemente do dispositivo de acesso. Para tanto, é frutífero explorar a noção de gêneros do discurso.

O russo Mikhail Bakhtin (1979) já dizia que cada esfera de utilização da língua elabora tipos relativamente estáveis de enunciados, sendo isso o que ele denominou de gêneros do discurso. Como afirma Bakhtin, a riqueza e a diversidade dos gêneros são infinitas, pois a variedade virtual da atividade humana é inesgotável, e cada esfera dessa atividade comporta um repertório de gêneros que se vai diferenciando e ampliando à medida que a própria esfera se desenvolve e fica mais complexa.

Os gêneros existem numa diversidade tão grande que muitas vezes se torna complicado estudá-los enquanto categorias. De fato, como colocar no mesmo pé de igualdade eventos audiovisuais tão distintos entre si, como uma narrativa de ficção seriada, a transmissão ao vivo de uma partida esportiva, o pronunciamento oficial de um presidente, um videoclipe, um debate político, uma aula de culinária, uma vinheta com motivos abstratos, uma missa ou um documentário sobre o fundo do mar? (Machado, 2001: 70-71)

Segundo Bakhtin, o indivíduo pode ignorar totalmente a existência teórica dos gêneros do discurso, mas, na prática, usa-os com segurança e destreza. Da mesma forma, Steger (apud Marcuschi, 1998) afirma que todos nós dominamos um saber intuitivo a respeito da adequação de textos em situações comunicativas. Todos nós temos uma competência socialmente adquirida que é usada para identificar textos individuais na relação com categorias mais gerais. Por exemplo, sabemos diferenciar uma telenovela de um filme ficcional ou de um programa humorístico de TV. Assim, os gêneros são "esferas de intenção", nas quais enunciados podem ser codificados e decodificados de forma mais ou menos estável, por uma comunidade de produtores e espectadores (Machado, 2001).

Para Jost, o gênero é como uma "moeda de troca que regula a circulação dos textos ou dos programas audiovisuais no mundo midiático" (2004: 27). Ou seja, tudo indica que existe um saber compartilhado socialmente pelo qual não só os falantes/escritores/diretores/produtores orientam suas decisões acerca dos gêneros textuais que devem construir em cada situação interacional, mas também os ouvintes/leitores/espectadores formulam condições de interpretação. Nesse sen- 
tido, como afirma Marcuschi (1998), os gêneros operam como geradores de expectativas de compreensão mútua. Todo gênero traz em si uma promessa de um mundo: "um documento, em sentido amplo, seja escrito ou audiovisual, é produzido em função de um tipo de crença visada pelo destinador" (Jost, 2004: 33).

Sobre o tema dos gêneros televisuais, Jost contribui de maneira precisa. Segundo o autor, "a primeira questão que se põe ao telespectador é saber se as imagens que ele vê remetem a objetos existentes ou a quimeras, entidades fictícias" (Ibid.), opondo gêneros informativos, como os telejornais ou os documentários, aos ficcionais, como filmes, telefilmes, seriados, telenovelas, sitcoms, entre outros. Ele considera que, na TV, são mais necessárias as "fronteiras que nós traçamos entre as imagens que remetem ao mundo e aquelas que representam um mundo eventualmente parecido com o nosso" (Ibid.: 34), muito embora essas oposições hoje em dia sejam tão somente virtuais e quase sem sentido.

Este é o papel do gênero [...]: fixar o grau de existência do mundo submetido ao leitor ou ao espectador. O gênero é uma promessa global sobre esta relação que vai propor um quadro de interpretação global aos atores ou aos acontecimentos representados em palavras, em sons ou em imagens. (Ibid.: 35)

Os gêneros são produtos culturais, sociais e históricos, formas socialmente maturadas em práticas comunicativas. Portanto, não são fruto de decisões individuais nem são facilmente manipuláveis. Fruto de trabalho coletivo, os gêneros contribuem para ordenar e estabilizar as atividades comunicativas do dia a dia. São de difícil definição formal, devendo ser contemplados em seus usos e condicionamentos sociopragmáticos e, assim como surgem, podem desaparecer. Enfim, como sintetiza Machado (2001), comentando os escritos de Bakhtin:

[...] o gênero é uma força aglutinadora e estabilizadora, um certo modo de organizar as ideias, meios e recursos expressivos, de modo a garantir a comunicabilidade e a continuidade do próprio gênero junto às comunidades futuras. Num certo sentido, é o gênero que orienta todo o uso da linguagem no âmbito de um determinado meio, pois é nele que se manifestam as tendências expressivas mais estáveis e mais organizadas da evolução de um meio, acumuladas ao longo de várias gerações de enunciadores. Mas, não se deve extrair daí a conclusão de que um gênero é necessariamente conservador. Por estarem inseridas na dinâmica de uma cultura, as tendências que preferencialmente se manifestam num gênero não se conservam ad infinitum, mas estão em contínua transformação no mesmo instante em que buscam garantir uma certa estabilização. (Ibid.: 68-69) 
Da passagem acima devemos ressaltar que, mesmo apresentando alto poder preditivo e interpretativo das ações humanas em qualquer contexto discursivo, os gêneros não são instrumentos estanques e enrijecedores da ação criativa. Caracterizam-se como eventos textuais altamente maleáveis, dinâmicos e plásticos. O gênero se renova em cada uma de suas obras individuais. À medida que vão surgindo novas práticas sociais ou novas tecnologias, vão aparecendo também novos gêneros.

Não é difícil constatar que, nos últimos séculos, foram as novas tecnologias, em especial as ligadas à área da comunicação, que propiciaram o surgimento de novos gêneros textuais. No entanto, vale salientar que não são propriamente as tecnologias que originam os gêneros, e sim a intensidade dos usos dessas tecnologias e suas interferências nas atividades comunicativas diárias. Seguramente, esses novos gêneros não são inovações absolutas, sem uma ancoragem em outros gêneros já existentes. O fato já fora notado por Bakhtin (1979: 277-326), que falava na transmutação dos gêneros e na assimilação de um gênero por outro, gerando novos. A tecnologia favorece o surgimento de formas inovadoras, mas não absolutamente novas. Veja-se o caso da telenovela. Ela tem uma ancoragem no folhetim e na radionovela, mas o canal é outro e, portanto, apresenta-se com características bem próprias. Isso mostra que, em alguns casos, será o próprio suporte ou ambiente em que os textos aparecem que determinam o gênero.

Machado (2001) lembra que os gêneros audiovisuais, em específico, são herdados da tradição, mas não somente da tradição televisual. Muitos são derivados da literatura, do cinema, do teatro, do jornalismo, e assim por diante. $\mathrm{O}$ mesmo vale para a ficção seriada, objeto deste artigo e um dos principais gêneros adotados pela televisão.

[...] não foi a televisão que criou a forma seriada de narrativa. Ela já existia antes nas formas epistolares de literatura (cartas, sermões, etc.), nas narrativas míticas intermináveis (As mil e uma noites), depois teve um imenso desenvolvimento com a técnica do folhetim, utilizada na literatura publicada em jornais do século passado, continuou com a tradição do radiodrama ou da radionovela e conheceu sua primeira versão audiovisual com os seriados do cinema. Na verdade, foi o cinema que forneceu o modelo básico de serialização audiovisual de que se vale hoje a televisão. (Ibid.: 86)

A televisão trouxe para a ficção seriada suas características próprias, transformando o gênero em uma forma particular, embora ainda se utilize dos elementos essenciais oriundos de outros meios que a antecederam, como a literatura, o rádio e o cinema. Em sua análise, Machado (2001) descreve certos tipos de ficção seriada que merecem ser evocados para tratar do ob- 
jeto particular deste estudo: as narrativas seriadas ficcionais produzidas pela Netflix. Sobre narrativas seriadas televisuais, ele elenca de maneira geral seus elementos indispensáveis, afirmando que:

Chamamos de serialidade essa apresentação descontínua e fragmentada do sintagma televisual. [...] o enredo é geralmente estruturado sob a forma de capitulos ou episódios, cada um deles apresentado em dia ou horário diferente e subdividido, por sua vez, em blocos menores, separados uns dos outros por breaks para a entrada de comerciais ou de chamadas para outros programas. (Machado, 2001: 83)

A consolidação da televisão por assinatura já proporcionou certas mudanças a esse princípio básico. Canais como $\mathrm{HBO}$ e Showtime, por exemplo, dispensaram o uso de intervalos comerciais em suas produções seriadas numa ruptura do fluxo originalmente proposto por Williams, que, como já mencionado, analisou uma era bem anterior à TV a cabo. Os episódios de seriados nesses canais são exibidos na íntegra durante todo o horário da grade, sem breaks, trazendo uma experiência sem interrupções e com tempo maior de exibição. Esse detalhe provocou fortes variações na maneira de estabelecer os momentos de maior tensão do enredo em um gênero de narrativa seriada.

Machado (2001) acreditava que, sem o uso de intervalos comerciais para que a audiência respirasse, haveria o risco de o interesse na narrativa diminuir, mas os hábitos do público certamente se adaptaram a essa nova oferta e permitiram a inovação no gênero. $\mathrm{O}$ autor concebe três tipos básicos de narrativa seriada - que, mais uma vez, não são exclusivas à experiência televisiva, embora na televisão tenham ganhado características particulares. No primeiro caso, de construção teleológica, uma única narrativa (ou várias entrelaçadas e paralelas) se sucede mais ou menos linearmente ao longo de todos os capítulos, como no caso da telenovela brasileira. Uma das marcas clássicas desse formato é o uso de ganchos de tensão - a última cena do capítulo é interrompida em um momento de grande suspense ou surpresa e só será continuada no capítulo seguinte. No segundo tipo, cada emissão é uma unidade autônoma, contando uma história de começo, meio e fim. No episódio seguinte, repetem-se apenas os personagens principais e o tipo de situação narrativa. Não há necessariamente uma ordem de apresentação dos episódios, sendo possível invertê-los sem que se perca o sentido da história. É o caso das comédias de situação americanas (sitcoms), como Two and a Half Men ou de dramas criminais como Lei e Ordem. No terceiro tipo de narrativa seriada, o único elemento que se preserva nos vários episódios é a temática das histórias: em cada unidade, a história é completamente 
diferente e vivida por diferentes personagens, atores, cenários e até diretores e roteiristas. A série nacional As Brasileiras segue esse estilo.

Na televisão, os três tipos de narrativa podem se confundir e, recentemente, têm se embaçado cada vez mais, gerando programas televisivos de linguagem bastante híbrida. Seriados estadunidenses de episódios autônomos já utilizavam recursos da construção narrativa teleológica. Por exemplo, Twin Peaks e Alias garantiram seu sucesso por alimentar os mistérios do enredo utilizando ganchos de tensão entre seus episódios e ao final de suas temporadas. Mas essa prática se tornou ainda mais recorrente nos dias de hoje: mesmo os sitcoms e os dramas criminais passaram a apresentar arcos narrativos que se desenrolam ao longo de vários episódios, ao fundo das histórias autônomas contadas em cada unidade narrativa. Autores como Jason Mittel já consideram que esse modelo "é singular no meio televisivo apesar das influências claras de outros formatos como as novelas, os filmes, os videogames e as histórias em quadrinhos" (2012: 32). De maneira inversa, as telenovelas brasileiras se apropriaram de características típicas dos seriados estadunidenses, como arcos narrativos curtos e de resolução mais rápida, dando um novo dinanismo ao ritmo narrativo.

Como já foi dito, essas transformações e hibridizações entre os tipos de narrativa são decorrentes da maleabilidade própria da linguagem, "havendo sempre um processo inevitável de metamorfose que os faz evoluir na direção de novas e distintas possibilidades" (Machado, 2001: 70). Indo mais além, é preciso destacar que, no cenário contemporâneo de disputa de intermídias, as diversas interferências tecnológicas trouxeram novos modos de fazer às indústrias de entretenimento, que agora tentam cada vez mais oferecer universos ficcionais complexos, se apropriando de formas cada vez mais sofisticadas de experimentação nas maneiras de narrar.

Mittel (2012) afirma que essas novas formas complexas não substituem as narrativas convencionais, que ainda são a maior parte da programação televisiva atual, mas que "um número suficientemente bem difundido de programas opera contra as práticas narrativas convencionais utilizando um conjunto de técnicas de narração" (Ibid.: 31). Segundo o autor:

Juntamente com a exibição de reconstituições dramáticas de crimes, das comédias do tipo sitcom e das competições em reality shows que povoam a programação da televisão americana, uma nova forma de entretenimento tem surgido nas últimas duas décadas, conseguindo sucesso de público e crítica. Tal modelo de storytelling para televisão se diferencia por usar a complexidade narrativa como uma alternativa às formas episódicas e seriadas que têm caracterizado a TV americana desde sua origem. (Ibid.: 30) 
Observando especificamente a produção televisiva estadunidense, Jason Mittell considera que as transformações na indústria midiática, nas tecnologias e no comportamento do público, embora não tenham sido a razão principal de tal mudança, coincidiram com o surgimento da complexidade narrativa de que o autor fala e possibilitaram o florescimento dessas novas estratégias criativas: "observamos tanto como essas transformações impactaram as práticas criativas e como os aspectos formais sempre se expandem para além das fronteiras textuais" (Mittell, 2012: 34). O autor identifica esse formato narrativo inovador em seriados como Lost, Arquivo X, Arrested Development e Veronica Mars, além das séries produzidas por canais fechados como o HBO.

Muito embora o texto narrativo televisual esteja nesse processo vivo de transformação, os gêneros ainda são determinantes para a experiência televisiva. Como foi visto, o telespectador sabe, de maneira intuitiva, o que lhe espera quando opta por assistir a um dos diversos tipos de narrativa seriada televisiva, e essa expectativa também é preservada mesmo quando a experiência de consumo se dá por outros dispositivos, como é o caso das séries da Netflix.

5. Devemos salientar que a Netflix não é a única prestadora de serviços de streaming no mundo. Podemos citar entre suas grandes concorrentes as empresas Hulu e a gigante do e-commerce Amazon, que também oferecem um acervo de vídeos sob demanda e também estão produzindo suas próprias séries na tentativa de disputar com a Netflix. Além disso, diversos canais de televisão aberta e fechada já estão oferecendo seus conteúdos por meio de streaming e produzindo conteúdos específicos para a plataforma web.

\section{NETFLIX: "QUEREMOS NOS TORNAR HBO”'}

"A Netflix revolucionou a maneira como as pessoas assistem a filmes e séries de TV" (Netflix, 2013, informação eletrônica). Criada em 1997 por Reed Hastings e Marc Randolph, a Netflix foi lançada com o propósito de oferecer o serviço de locação de filmes online. Dois anos depois, a empresa incorporou o serviço de assinatura mensal, disponibilizando, a um valor relativamente baixo, acesso ilimitado ao catálogo da empresa. A partir daí, foi conquistando assinantes. Em 2002, terminou o ano com 857 mil usuários, $88 \%$ a mais que no ano anterior (Ibid.). Em, 2007 lançou o serviço de streaming, ou seja, assistir online instantaneamente sem precisar baixar os arquivos. A empresa chegou ao mercado brasileiro em 2011 junto com toda a América Latina e Caribe. Hoje, presente em mais de 40 países e líder no segmento de conteúdos de vídeo sob demanda, a Netflix soma mais de $30 \mathrm{mi}$ lhões de clientes nos Estados Unidos e oito milhões pelo mundo (Junqueira, 2013, informação eletrônica).

Por um preço mensal baixo, os assinantes Netflix podem assistir quantos filmes e séries quiserem, quando e onde quiserem, em praticamente qualquer tela com conexão à Internet. Os assinantes podem assistir, pausar e voltar a assistir a um título sem comerciais e sem compromisso (Netflix, 2013, informação eletrônica). 
Em 2011, a Netflix, que até então apenas disponibilizava títulos previamente produzidos e distribuídos por estúdios de televisão ou de cinema, anunciou que iria investir em suas próprias produções originais, lançando, em 2012, a comédia Lilyhammer, coproduzida pela emissora televisiva norueguesa NRK1. Os oito episódios da primeira temporada da série foram exibidos primeiro na Noruega e, um mês depois, a Netflix disponibilizou toda a temporada para seus assinantes.

Foi a partir de 2013 que a empresa começou a apostar alto nesse filão, disponibilizando sucessivos títulos exclusivamente. De acordo com o diretor de conteúdo da empresa, Ted Sarandos, a Netflix quer se "tornar HBO antes que a HBO se torne Netflix" (Sarandos apud Condliffe, 2013, informação eletrônica). Essa citação demonstra que o canal fechado estadunidense é tido como uma referência, um padrão de qualidade no que diz respeito à ficção televisiva para audiências de nicho, ao qual a Netflix deseja se equiparar.

Até o momento deste artigo, diversos produtos audiovisuais já foram pensados e lançados pela empresa, explorando diversos gêneros e nichos de interesse. Para esta análise, vamos nos ater aos três seriados originais que mais chamaram a atenção do público e da crítica mundiais: o drama político House of Cards, o suspense fantástico Hemlock Grove e a comédia dramática Orange is the New Black. A maioria das produções envolvereu elenco renomado, tanto no cinema quanto na televisão. Outras produções incluem a quarta temporada da comédia seriada Arrested Development, antes produzida pelos estúdios Fox, a comédia Derek, a minissérie brasileira $A$ Toca, com o comediante Felipe Neto e a série infantil de animação Turbo, em parceria com o estúdio DreamWorks.

Protagonizada pelo ator vencedor do Oscar Kevin Spacey e dirigida por David Fincher, House of Cards é uma adaptação do romance homônimo escrito por Michael Dobbs e da minissérie produzida pelo canal britânico BBC. A série conta a história de Frank Underwood, político ambicioso que quer ocupar um alto cargo público em Washington. Com 13 episódios, a primeira temporada foi divulgada na íntegra no dia $1^{\circ}$ de fevereiro de 2013 . A segunda temporada da série foi disponbilizada no dia 14 de fevereiro de 2014.

Na linha de séries como American Horror Story, do canal a cabo FX, Hemlock Grove investe no terror. No seriado, uma jovem é assassinada e encontrada perto de uma antiga fábrica de aço, na cidade fictícia Hemlock Grove. Dois suspeitos pelo crime, um garoto que supostamente é um lobisomem e o herdeiro da propriedade Godfrey, resolvem encontrar o verdadeiro assassino sozinhos. A história é baseada no romance de mesmo título de Brian McGreevy, lançado no primeiro semestre de 2012. Foi disponibilizada a partir de abril de 2013. 
Inspirada na autobiografia de Piper Kerman, Orange is the New Black relata as experiências vividas pela personagem Piper Chapman, quando ela é condenada a uma sentença de um ano e meio na prisão. A série de tom tragicômico foi criada por Jenji Kohan, que já havia garantido sucesso na TV a cabo com a comédia Weeds. A primeira temporada de Orange foi lançada pela Netflix em julho de 2013 e mesmo antes da liberação dos episódios ela já havia sido renovada para um segundo ano.

Essas produções originais da Netflix foram disponibilizadas apenas pelo próprio serviço da empresa. Ainda assim, todos os produtos foram pensados na lógica de temporadas, unidade típica dos seriados estadunidenses, que normalmente comporta um conjunto de 12 ou 13 episódios, no caso dos canais pagos, e que pode ir até 24 episódios na TV aberta. A diferença é que, em vez de disponibilizar um episódio a cada semana, como nos canais televisivos ou mesmo nos canais de YouTube, a Netflix lança os episódios de suas produções originais de uma só vez, para que possam ser consumidos da maneira que o assinante preferir. Assim, o usuário pode assistir à temporada inteira em apenas um dia, se assim o quiser.

Apesar dessa diferença, as séries da Netflix reúnem elementos comuns aos produtos de ficção seriada televisiva. A entrega dos episódios é feita de modo similar à do DVD, rompendo com a noção tradicional de grade televisiva numa prática que permite que o espectador determine seu próprio fluxo e ponto de acesso, conforme previsto por Lotz (2007). Isso porque, a partir de estudos sobre os hábitos dos seus próprios assinantes, a Netflix identificou que $61 \%$ os usuários preferem assistir a vários episódios de uma mesma série em sequência (Fallon, 2014), numa prática apelidada de binge-viewing. Entretanto, não há grandes novidades do ponto de vista da linguagem: as produções aproveitam elementos de seu respectivo gênero televisivo para atrair público e garantir seu sucesso.

\section{SÉRIES ORIGINAIS NETFLIX E RECORRÊNCIAS TEXTUAIS DE GÊNEROS TELEVISIVOS}

A HBO se tornou referência em qualidade de televisão ao afirmar, justamente, que não era televisão. O slogan "It's not TV. It's HBO" foi o lema da empresa dos anos 1996 a 2009, numa época em que o canal consolidava seu sucesso no mercado com produções ousadas, que exploravam temas espinhosos, como drogas, homossexualidade e crime, sem se esquivar de nudez e violência. Tais produções se tornaram evidência do que Mittell (2012) chama de complexidade narrativa na televisão.

Séries aclamadas pelo público e pela crítica, como A Família Soprano, A Sete Palmos, Sex and the City e $\mathrm{O} z$, trouxeram tramas complexas e bem estrutu- 
radas, além de personagens profundos que contrariavam a noção maniqueísta de protagonista herói. Ao impor um novo padrão de qualidade de televisão, a $\mathrm{HBO}$ e outros canais pagos similares inovaram nos gêneros e provocaram mudanças na ficção seriada que mais tarde iriam se difundir para outras emissoras.

A HBO construiu sua reputação e garantiu um número de assinantes com base em programas narrativamente complexos, como The Sopranos, Six Feet Under, Curb your Enthusiasm e The Wire. Esses programas oferecem claramente uma alternativa à narrativa televisiva convencional. (Mittell, 2012: 30)

As produções do canal apostam em protagonistas anti-heróis, de natureza falha e com nuances que buscam se aproximar da realidade, além de tramas intrincadas e aprofundadas que continuam ao longo de vários episódios, com ganchos de tensão em momentos estratégicos, combinando as estruturas de narração seriada episódica e teleológica, marca central da narrativa complexa, para Mittell. Além disso, investem em formas inovadoras e criativas de narrar, se apropriando de recursos estilísticos dos mais diversos gêneros narrativos televisuais.

Recusando a necessidade de fechamento da trama em cada episódio, que caracteriza o formato episódico convencional, a complexidade narrativa privilegia estórias com continuidade e passando por diversos gêneros. [...] na programação narrativamente complexa, o desenvolvimento da trama tem posição muito mais central, possibilitando emergir um relacionamento e um drama associado às personagens a partir do desenrolar do enredo e, dessa forma, atribui ênfase de maneira reversa às novelas. (Ibid.: 37)

Como no surgimento de toda tecnologia, a Netflix se apropria de gêneros que já fazem parte do repertório dos seus usuários para criar suas produções originais, trazendo produtos que apresentam os principais elementos e estética de uma série vista na televisão (especificamente de canais pagos): enredos polêmicos, personagens protagonistas de caráter duvidoso e contraditório. Tudo com a tentativa de atrair nichos de audiência, compreendendo o cenário do consumidor contemporâneo.

Certamente as mudanças na indústria televisiva ajudaram a reforçar as estratégias para a complexidade. [...] conforme o número de canais cresceu e a audiência de qualquer tipo de programa foi reduzida, as redes de televisão e seus canais acabaram por reconhecer que para um programa ser economicamente viável pode ser suficiente um público seguidor pequeno, porém dedicado. (Ibid.: 34) 
As produções da Netflix bebem nessa fonte, também buscando apresentar narrativas complexas, nos termos de Mittell, de estética bastante similar à das séries produzidas pela $\mathrm{HBO}$ e outros canais, em busca de um "público reduzido composto por espectadores com maior grau de instrução e que normalmente evitariam a televisão" (Ibid.: 34). Analisando mais de perto os dramas de uma hora House of Cards, Hemlock Grove e Orange is the New Black, as primeiras características não se diferenciam muito das séries de canais pagos. Como já foi dito, todos se dividem na lógica de temporadas, sendo que apenas House of Cards já teve sua segunda temporada lançada, até o momento deste artigo. As temporadas possuem 13 episódios, número também praticado pela maior parte dos canais pagos estadunidenses.

Em média, cada episódio tem cerca de 50 minutos, podendo chegar até pouco mais de uma hora em seus momentos mais dramáticos. O primeiro e o último episódio da temporada costumam ser um pouco mais longos do que os demais, por seu caráter especial. Esse também é o tempo de exibição padrão de séries em canais pagos, nos quais não há a inserção de intervalos comerciais fragmentando a fluidez da narrativa.

No início de cada episódio, uma vinheta de abertura de pouco mais de um minuto ambienta o espectador e dá o tom da série. A abertura é um elemento que tem sido um pouco deixado de lado pelos canais abertos estadunidenses, para privilegiar o tempo de exibição do programa, mas que ainda é muito utilizado pelos canais pagos de maneira geral, ganhando um caráter artístico. HBO, Starz e Showtime, entre outros, costumam produzir vinhetas de abertura com muito esmero e riqueza de detalhes, usando trilha sonora original, buscando capturar, ao mesmo tempo, a plástica e o conteúdo da série.

A Netflix não fez diferente, apostando em aberturas de evidente preocupação estética e que apresentam o ambiente das séries. House of Cards traz uma sequência de imagens de Washington e seus principais monumentos, que são exibidas em timelapse acelerado, combinadas a uma trilha sonora impactante. Já a sequência inicial de Orange is the New Black mostra uma série de imagens praticamente estáticas, explorando planos com detalhes de rostos das presidiárias. A abertura de Hemlock Grove procura estabelecer o clima sinistro, com ilustrações bizarras e o uso de imagens formadas digitalmente por fumaça.

Ao descrever os gêneros de ficção seriada, Machado (2001) afirma que, no início dos episódios, é comum haver uma rápida montagem que busca retomar os principais acontecimentos da série, "uma pequena contextualização do que estava acontecendo antes (para refrescar a memória [...])" (Ibid.: 83). No caso das séries da Netflix, como não há um intervalo imposto entre cada emissão, esse recurso não seria necessário em todos os episódios. Além dis- 
so, o espectador está livre para, em qualquer momento, usar recursos como pausar, retroceder ou assistir novamente a um episódio anterior, tornando essa contextualização redundante. Ainda assim, entre a primeira e a segunda temporada de House of Cards, a Netflix disponibilizou um episódio especial que buscava resumir os eventos passados na série, para que os espectadores não se perdessem e para manter o fôlego da série, mostrando como o uso desse recurso ainda é pertinente mesmo numa experiência sob demanda.

Apesar de cada episódio funcionar como uma unidade narrativa autônoma com início, meio e fim, em correspondência ao segundo tipo de narrativa seriada descrita por Arlindo Machado (2001), todas as séries possuem arcos narrativos prolongados, que só se resolvem no decorrer de várias emissões, um recurso de ordem teleológica. Frequentemente, há o uso de um gancho de tensão "que visa manter o interesse do espectador" (Ibid.: 83) e motivá-lo a assistir ao episódio seguinte. Como foi dito, esse hibridismo entre tipos narrativos já é característico dos gêneros televisuais e tais recursos já são previstos por Machado (2001) como elementos textuais integrantes do gênero da narrativa seriada televisiva.

A diferença fundamental é que, dentro da grade de programação, há, necessariamente, um espaço de tempo entre uma emissão e outra - no caso de seriados, normalmente, as emissões são semanais. Assim, os ganchos de tensão inseridos ao final dos episódios ou capítulos servem para estabelecer a sensação de suspense até a exibição seguinte. No caso da Netflix, os ganchos ganham a finalidade não somente de manter o espectador interessado na trama, mas também de estimular a prática de binge-viewing, ou seja, de consumir vários episódios de um mesmo programa em sequência, dentro de um intervalo de tempo menor.

Entre uma temporada e outra, no entanto, há cerca de um ano de espera para que os novos episódios sejam disponibilizados na plataforma. Para encerrar com todo o fôlego e prender a atenção da audiência, o último momento da temporada é normalmente marcado por um surpreendente gancho de tensão, que deixa sua resolução para a temporada seguinte. O final da primeira temporada de Orange is the New Black, como exemplo mais significativo do uso desse recurso entre as séries em questão, mostra a protagonista Piper Chapman se envolvendo numa briga sangrenta com outra presidiária, mas o desfecho da disputa fica em suspenso e a resolução só será apresentada no início da temporada seguinte.

Em relação ao enredo e à construção de personagens, todas as séries analisadas possuem protagonistas de natureza aprofundada, com nuances e contradições, evitando o chavão do herói e da mocinha das narrativas convencionais. Em House of Cards, o personagem principal e narrador é Francis Frank Underwood, político que almeja a cadeira de Secretário do Estado. Ardiloso, inescrupuloso e ganancioso, Underwood não mede esforços para ganhar mais 
poder no cenário político estadunidense, manipulando todos os personagens que o circundam em favor de seus próprios interesses. Quase todos os outros personagens da trama seguem a mesma linha, rendendo enredos de conspiração e com reviravoltas constantes. Já a Piper Chapman de Orange is the New Black é egoísta, contraditória, impulsiva e volúvel, apesar de se esforçar, na maior parte do tempo, para ser uma pessoa de boa índole. Seu comportamento, e inclusive sua orientação sexual, oscilam ao longo de toda a série. $\mathrm{O}$ mesmo tipo de construção de personagem se reproduz para Hemlock Grove, que trabalha com diversos núcleos de personagens.

A diversidade de personagens coadjuvantes também é marca dessas séries. Como Orange is the New Black se passa em um presídio feminino, a quantidade de personagens é muito vasta e, a cada episódio, são apresentados flashbacks que contam um pouco da história de uma das presas, antes de chegar até ali. Esses flashbacks são intercalados à trama que está sendo contada no presente e lembram o formato que ficou muito popularizado após a série Lost, que também lidava com um grande número de personagens. Desse modo, a série apresenta uma gama de narrativas que independem da sua protagonista, de maneira similar às telenovelas brasileiras, que possuem diversos núcleos de personagens.

Dessa maneira, a Netflix se apropria do gênero de narrativa seriada televisiva, aproveitando elementos que já são bem conhecidos e típicos de sua formatação e ainda não promovendo fortes inovações do ponto de vista da linguagem. A nova experiência de consumo, em que os espectadores parecem preferir assistir a vários episódios de uma mesma série em sequência, pode vir a promover rupturas textuais significativas no futuro.

\section{CONSIDERAÇÕES FINAIS}

Diante do exposto e do cenário de transformação midiática contemporâneo, talvez a definição de televisão permaneça nebulosa por algum tempo e o tema careça ainda de muitas discussões. No que diz respeito à Netflix, podemos observar que a empresa se insere nesse contexto, oferecendo produtos que não se distanciam dos gêneros televisivos a ponto de serem nomeados de outra forma, embora sua forma de emissão não seja aquela do fluxo característico do broadcasting. A produtora investe em formas complexas de narrativas, se apropriando de recursos já observados em canais pagos de televisão, como forma de atender à demanda de audiências segmentadas e multiplataforma.

O dispositivo televisivo remete muitas vezes à noção de fluxo, responsável por impor ao telespectador a sua programação imutável, ditando regras do que ver e da hora de ver. A Netflix surge como uma alternativa à regra, 
aproveitando recorrências textuais que as emissoras de TV aberta e a cabo já haviam consolidado, de modo que sua programação original ainda não deixa de ser considerada como texto televisivo, embora, mais para frente, possa promover mudanças mais evidentes no texto do gênero da narrativa seriada televisiva. Como indicação para trabalhos futuros, está a de observar como a Netflix se utiliza de formas complexas de narrativa para produzir conteúdos diferenciados, do ponto de vista estético.

A depender da democratização do acesso à internet, a Netflix poderá, em pouco tempo, ser a responsável por uma completa mudança de paradigma na forma como a audiência consome TV, embora isso ainda não tenha proporcionado mudanças aos gêneros narrativos em si. Seria mais uma grande transformação da TV aberta? Resta esperar para ver se a plataforma vai atender à demanda dos telespectadores ou se será preciso uma revolução silenciosa da audiência, que pouco a pouco migre para outras plataformas de modo a acessar seu conteúdo.

Outra barreira a ser vencida nesse processo de reformulação da plataforma é a forma como se pensa garantir a audiência. Do modo como está pautada hoje, a TV oferece doses diárias de narrativa de modo a manter a fidelidade dos telespectadores. No entanto, a Netflix mostra que é possível manter o indivíduo fiel à plataforma mesmo disponibilizando seu conteúdo de uma só vez.

É preciso avaliar ainda se a massa de telespectadores, com suas diversas dinâmicas, está preparada para entender as mudanças e adaptar-se a elas. No entanto, tomando como amostra a população conectada ao Netflix, é possível considerar que a transição não será traumática e talvez contribua ainda para o maior consumo dos conteúdos, já que isso poderá ser feito a partir da conveniência da audiência e não mais do emissor. $\mathbf{M}$

\section{REFERÊNCIAS}

ÁVAREZ MONZONCILLO, José María. Las nuevas televisiones: personalización e individualización. In: . La Televisión Etiquetada: nuevas audiências, nuevos negocios. Madrid: Fundación Telefónica, 2011. p. 83-101.

BAKHTIN, M. Os gêneros do discurso. In: Estética da criação verbal. São Paulo: Martins Fontes, 1992. p. 277-326.

CARR, D. TV foresees its future. Netflix is there. New York Times, 22 jul. 2013. Disponível em: <http://www.nytimes.com/2013/07/22/business/media/ tv-foresees-its-future- netflix-is-there.html? pagewanted=all $>$. Acesso em: 30 jul. 2013.

CONDLIFFE, J. Netflix: the goal is to become HBO faster than $\mathrm{HBO}$ can become us. Gizmodo, 30 jan. 2013. Disponível em: <http://gizmodo. 
com/5980103/netflix-the-goal-is-to-become-hbo-faster-than-hbo-can become-us $>$. Acesso em: 30 jul. 2013.

EVANS, E. Transmedia television: audiences, new media, and daily life. Nova York/Londres: Routledge, 2011.

FALLON, K. Why we binge-watch television? The Daily Beast. 8 jan. 2014. Disponível em: <http://www.thedailybeast.com/articles/2014/01/08/ why-we-binge-watch-television.html>. Acesso em: 24 jan. 2014.

FECHINE, Y. A programação da TV no cenário de digitalização dos meios: configurações que emergem dos reality shows. In: FREIRE FILHO, João (org). A TV em Transição. Porto Alegre: Sulina, 2009. p. 139-170.

JOST, F. Seis lições sobre televisão. Porto Alegre: Sulina, 2004.

JUNQUEIRA, D. Netflix cresce no Brasil mesmo após aumento na mensalidade e quer produzir documentários e stand-up comedy. Gizmodo Brasil. 22 jul. 2013. Disponível em: <http://gizmodo.uol.com.br/netfli$\mathrm{x}$-cresce-no-brasil-mesmo-apos-aumento-na-mensalidade-e-quer-produzir-documentarios-e-stand-up-comedy/>. Acesso em: 30 jul. 2013.

LOTZ, A. D. The television will be revolutionized. Nova York/Londres: New York University Press, 2007.

MACHADO, A. A televisão levada a sério. São Paulo: Senac, 2001.

MARCUSCHI, L. A. Da fala para a escrita: atividades de retextualização. 2 ed. São Paulo: Cortez, 1998.

MILLER, T. A televisão acabou, a televisão virou coisa do passado, a televisão já era. In: FREIRE FILHO, J. (Org.). A TV em transição. Porto Alegre: Sulina, 2009, p. 9-25.

MITTELL, J. Complexidade narrativa na televisão americana contemporânea. MATRIZes. São Paulo, ano 5, no 2, p. 29-52, jan/jun. 2012. DOI: <http:// dx.doi.org/10.11606/issn.1982-8160.v5i2p29-52>.

NETFLIX. Disponível em: <www.netflix.com>. Acesso em: 30 jul. 2013.

URICHIO, W. Contextualizing the broadcast era: nation, commerce, and constraint. The ANNALS of the American Academy of Political and Social Science, vol. $625 \mathrm{n}^{\circ} 1$, set. 2009.

WILLIAMS, R. Television: technology and cultural form. Nova York: Schoken Books, 2004.

Artigo recebido em 23 de outubro de 2014 e aprovado em 28 de abril de 2015. 